\title{
Multiscale characterization of streamflow and suspended sediment concentration data using Hilbert-Huang transform and time dependent intrinsic correlation analysis
}

\author{
S. Adarsh ${ }^{1,2} \cdot$ M. Janga Reddy
}

Received: 31 October 2016/Accepted: 2 November 2016/Published online: 11 November 2016

(C) Springer International Publishing Switzerland 2016

\begin{abstract}
In this paper, Hilbert-Huang transform method is applied for the characteristic analysis of monthly streamflow and total suspended sediment (TSS) concentration time series from two stations, Basantpur and Tikrapara in Mahanadi basin, India. All the four time series are first decomposed by the complete ensemble empirical mode decomposition with adaptive noise method into different Intrinsic Mode Functions (IMFs) with specific periodicity and the IMFs are subsequently subjected to the Hilbert transform. The multiscale decomposition clearly detected the annual cycle in all the four time series and statistical significance test of the IMF components showed that the annual and inter annual cycles are significant in deciding the variability of the series except for the streamflow of Tikrapara station. The cross correlation analysis found a direct association between streamflow and TSS in most of the time scales except in the residue. Finally, the time dependent intrinsic correlation (TDIC) analysis is employed to find the association between streamflow and TSS in different time scales. The TDIC analysis proved the existence of long range direct correlation between the two series at intra-annual and annual time scales for the data from both of the stations. From TDIC analysis, it is further noticed that the nature of association between streamflow and sediment concentration is not of unique character always but varies with time scales and in time domain and many reversals of associations are observable at inter annual scales. The
\end{abstract}

S. Adarsh

adarsh.sankaran@yahoo.in

1 Department of Civil Engineering, Indian Institute of Technology Bombay, Powai, Mumbai 400076, India

2 TKM College of Engineering Kollam, Kollam, Kerala 691005, India negative association between streamflow and sediment concentration is more perceptible in the data from Tikrapara station than that from Basantpur and it infers the influence of internal forcing such as human interventions and basin characteristics.

Keywords Amplitude $\cdot$ Frequency $\cdot$ Hilbert-Huang transform - Sediment $\cdot$ Streamflow $\cdot$ Time dependent intrinsic correlation

\section{Introduction}

Characterization of sediment transport processes in rivers is of paramount importance in the planning and management of hydraulic structures. Semi-arid rivers experiencing pronounced wet and dry seasons often display high variability in the sediment-streamflow relationship (Farnsworth and Milliman 2003; Warrick and Mertes 2009; Gray et al. 2014). Larger temporal scale corresponds to a slower variation of the physical quantity in time (such as the bed elevation changes) while smaller time scale corresponds to rapid variations (such as variations of flow). Such information on multiple temporal scales may lead to a singularly perturbed behavior and used to justify the decoupled sediment transport models (Lyn 1987). Therefore, identification and selection of such multiple scales associated with sediment concentration time series data from natural channels may help for accurate modeling of sediment transport processes and it may be helpful in development of a suitable bed load transport formulas (Ancey et al. 2006, 2008; Kuai and Tsai 2012). Variability in suspended sediment concentration and streamflow is determined by internal and external mechanisms that are highly dependent on temporal scale (Carson et al. 1973; Gao et al. 2007; 
Florsheim et al. 2011; Kuai and Tsai 2012). Streamflow and sediment load are influenced by climate cycles and human activities, and their influence varies with time scales. Hence, it is important to understand the exact reason behind the changes and accordingly the studies should be delineated (Syvitski 2003; Syvitski et al. 2005).

A number of studies have investigated changes in sediment load and streamflow, associated underlying causes and subsequent impacts (e.g., Zhang et al. 2008, 2009, 2012, 2014; Chen et al. 2010a). Zhang et al. (2008) analysed time series of annual water discharge and sediment loads (1950s2004) at nine stations in the main channels and main tributaries of the Zhujiang (Pearl River) basin, demonstrating a significantly decreasing sediment load at some stations in the main tributaries and more stations have witnessed significantly decreasing sediment loads since the 1990s. They also indicated that the decreasing sediment load of the Pearl River basin was the result of hydrological regulations of water reservoirs. Zhang et al. (2009) analysed monthly streamflow and sediment load records of Datong station in Yangtze river using scanning $t$ test, $F$ test and coherency analysis. Zhang et al. (2012) applied similar techniques to analyse the streamflow and sediment load from nine hydrological stations of Pearl River and possible implications were discussed. Zhang et al. (2014) analysed the variability of stream flow from four hydrological stations on East River, China using Ensemble Empirical Mode Decomposition (EEMD) and Continuous Wavelet Transform (CWT) methods. In the Indian context, Gupta and Chakrapani (2005) analysed the spatial and temporal variations of streamflow and sediment load in Narmada basin. Following traditional trend analysis procedures Panda et al. (2011) reported that there is a reducing trend in sediment load series from different river basins in India and identified that human interventions is the major driver behind such reductions. Adarsh et al. (2016) performed a rigorous trend analysis study of sediment load time series from different basin outlets in India using non-parametric tests and empirical mode decomposition (EMD). Subsequently, they detected the role of human interventions on the sediment load variability in these stations employing the CWT analysis. It is also essential to conduct such studies (on sediment load and streamflow variations) in multiple time scales, upon data from various regions, to understand the stable and unstable properties of hydrological processes at different time scales, and also to identify the possible causes and implications of construction of storage reservoirs, etc. To identify such multiple time scale of variability and subsequent interpretations spectral analysis procedures are helpful.

The traditional Fourier based spectral analysis method may be inappropriate in the case of existence of multiple time scales of variability. Moreover, the Fourier analysis is suited well only for linear and stationary time series, which is often rare to observe such properties in the hydrological time series. Therefore, it is more appropriate to perform the spectral analysis of sediment concentration and associated streamflow in a multiscale framework. Wavelets are alternative spectral analysis tools suitable for analyzing nonstationary time series, but not well suited to analyse time series of non-linear characteristics. Also, their capabilities are often influenced by the selection of appropriate mother wavelet function and selection of appropriate levels of decomposition. As an alternative to wavelets, a fully data adaptive multiscale decomposition method namely EMD was proposed by Huang et al. (1998) to get orthogonal modes namely intrinsic mode functions (IMFs). Its use in conjunction with the Hilbert transform contributed an attractive spectral analysis tool namely Hilbert-Huang transform (HHT) to analyse non-linear and non-stationary time series data. Over the years, many variants of HHT were evolved, and most of them attempted to resolve the issues of (1) existence of a particular mode in multiple time scales (popularly known as mode mixing, which can lead to misinterpretation of spectra), (2) lack of mathematical correctness of Hilbert transform. To address the first issue, noise assisted data analysis methods such as ensemble EMD (EEMD) (Wu and Huang 2005a) and the complete EEMD with adaptive noise (CEEMDAN) (Torres et al. 2011) were proposed. To address the second issue, normalization and direct quadrature scheme was proposed by Huang et al. (2009b). The potential of HHT and its variants attracted many researchers and it is gaining popularity for the analysis of hydrologic time series, which are often nonlinear and non-stationary in characteristics (Rao and Hsu 2008; Huang and Wu 2008; Huang et al. 2009a; Rudi et al. 2010; Franceschini and Tsai 2010; Kuai and Tsai 2012; Massei and Fournier 2012; Antico et al. 2014; Adarsh and Janga Reddy 2015, 2016; Janga Reddy and Adarsh 2016).

Kuai and Tsai (2012) applied the HHT for the identification of varying time scale in sediment transport process by gathering both bed load and suspended sediment concentration data. They found the multiple scales involved in sediment transport process, succession of time scales by the comparison of HHT spectra of streamflow and the sediment data and noticed that the dominant time scale is time varying in characteristics. Also the above study verified the HHT results by one of the popular time scale formula proposed by Cao et al. (2007). But they didn't attempt to quantitatively ascertain the link between streamflow and suspended sediment concentration. The streamflow-sediment concentration interactions in rivers are influenced by lot of complex internal mechanisms primarily related to the characteristics of the basin and external mechanisms such as climatic and solar forcings (Gray et al. 2014). Also, as the time series of hydrologic variables are controlled by different physical processes (each has specific time scale of 
variability), it is more appropriate to investigate the linkage between streamflow and sediment concentration in a multiscale framework. It is also noted that there were not much studies carried in the past to investigate such linkages using efficient multiscale spectral analysis procedure such as HHT and multiscale correlation analysis like time dependent intrinsic correlation (TDIC).

Thus the specific objectives of the present study include (1) perform the spectral analysis of total suspended sediment (TSS) concentration and streamflow data from a tropical river in India using HHT for their characterization in multiple time scales; (2) quantitatively investigate the link between streamflow and TSS concentration by HHT based TDIC method, to capture the relative effect of anthropogenic interventions and climate forcings on the variability of the time series.

The rest of the paper is organized as follows: first a brief theoretical background and details of CEEMDAN and HT methods are presented; subsequently, a brief description of the study area and details of datasets used are presented; the results and discussion of case study are presented thereafter.

\section{Materials and methods}

Hilbert-Huang transform (HHT) is a popular spectral analysis tool for analyzing nonlinear and non-stationary time series data. The HHT method involves two phases: (1) a multiscale decomposition of time series to get orthogonal modes called IMFs, (2) the Hilbert transform (HT) of the obtained IMFs. A typical EMD process consists of (1) the identification of local extrema points and fitting of spline functions connecting them, (2) computation of the mean series (of extrema) and find a residue series (obtained by subtraction of mean from the original series). The above process is known as 'sifting' and the sifting operation is iteratively continued till the resulting series become a zero mean series with total number of extrema differ from the summation of number of local maxima and local minima points at the most by one. The process is repeated till the final residue series is monotonic or contains only one peak. A detailed description on the EMD can be found in Rao and Hsu (2008). The obtained IMFs, sometime may exhibit 'mode mixing', and to overcome such problems, Wu and Huang (2005a) proposed the EEMD approach. In EEMD, an ensemble of artificial signals is formed by adding randomly generated white noise series with the original signal. The EMD is performed upon all artificial signals and the ensemble averaging of each mode will give the true IMF component. But it was observed that the final IMF obtained by the ensemble averaging many not always possesses the properties of an IMF. Also the reconstructed signals may contain residual noise and the mode mixing problem may prevail when applied to real field data (Antico et al. 2014). To overcome such problems an improved method namely the complete EEMD with adaptive noise (CEEMDAN) proposed by Torres et al. (2011) can be used for the analysis of real field data. The superiority of CEEMDAN over the EMD and EEMD in applications to hydrological time series was highlighted in some recent studies (Marusiak and Pekar 2014; Antico et al. 2014). The basic procedure of CEEMDAN on a time series $X(t)$ is presented below:

1. Perform the EMD for $M$ realizations $X_{m}(t)=$ $X(t)+\varepsilon_{0} w_{m}(t)$ and compute the first mode of CEEMDAN $\overline{\overline{I M F_{1}(t)}}$, by averaging the realizations

$\overline{\overline{I M F_{1}(t)}}=\frac{1}{M} \sum_{m=1}^{M} I M F_{m}(t)$,

where $m$ is the index for realizations; $\varepsilon_{o}$ is the noise parameter for the initial step and $w_{m}(t)$ is the white noise series added to the candidate signal.

2. At the first stage $(k=1)$ calculate the unique first residue as,

$R_{1}(t)=X(t)-\overline{\overline{I M F_{1}(t)}}$.

3. Decompose realizations $R_{1 m}(t)=R_{1}(t)+\varepsilon_{1} E_{1}\left(w_{m}(t)\right)$, $m=1,2, \ldots, M$ until their first EMD mode gets evolved. Then compute the second mode $\overline{\overline{I M F_{2}(t)}}$

$\overline{\overline{I M F_{2}(t)}}=\frac{1}{M} \sum_{m=1}^{M} E_{1}\left[R_{1}(t)+\varepsilon_{1} E_{1}\left(w_{m}(t)\right]\right.$,

where $\varepsilon_{1}$ is noise parameter for stage $1(k=1)$; the operator $E_{k}($.$) is an operator represents the evolution of$ the $k$ th mode by EMD.

4. Calculate the $k$ th residue as,

$R_{k}(t)=R_{k-1}(t)-\overline{\overline{I M F_{k}(t)}}$ for $k=2,3, \ldots, K$,

where $\overline{\overline{I M F_{k}(t)}}$ is the IMFs obtained by CEEMDAN.

5. Compute the first EMD mode of $R_{k}(t)+\varepsilon_{k} E_{k}\left(w_{m}(t)\right)$, and define the $(k+1)$ th mode by CEEMDAN as

$\overline{\overline{I M F_{k+1}(t)}}=\frac{1}{M} \sum_{m=1}^{M} E_{1}\left[R_{k}(t)+\varepsilon_{k} E_{k}\left(w_{m}(t)\right]\right.$.

6. Go to step (4) for next $k$. Steps 4-6 are performed until the obtained residue is no longer feasible to be decomposed (i.e., the residue is monotonic or having only one extrema). The residue is given by

$$
R_{K}(t)=X(t)-\sum_{k=1}^{K} \overline{\overline{I M F_{k}(t)}}
$$

The obtained IMFs are the most appropriate inputs to perform the Hilbert transform which may help to study the 
spectral characteristics of a nonlinear and non-stationary time series in the time-frequency domain. The HT is the convolution of supplied signal with the function $g(t)=1 /$ $\pi t$.

The basic principle of Hilbert transform is the formation of a complex signal by an IMF and its HT (say $Y(t)$ ). Then the square root of squared sum of the signal $(\operatorname{IMF}(t))$ and its HT at any time instant gives the instantaneous amplitude. The inverse tangent of the ratio of $Y(t)$ and $\operatorname{IMF}(t)$ gives the phase angle and the time derivative of the phase angle gives the instantaneous frequency. The mathematical background of HT can be found in Huang et al. (1998) or Rao and Hsu (2008). The traditional HT may sometimes lead to instantaneous frequencies that are of less physical meaning (such as negative frequency) or it may fail to address the problems related to disjoint functions and mathematical incorrectness stated in Bedrosian theorem (Bedrosian 1963) and Nuttal theorem (Nuttal 1966). To ensure that the obtained IMFs are physically meaningful and mathematically correct, Huang et al. (2009b) proposed a normalization and direct quadrature schemes for the HT. The normalization scheme primarily involves: (1) identification of local maxima of IMF series, (2) spline fitting through local maxima points; (3) term by term division of IMFs by the constructed spline, and this step is to be repeated iteratively till the normalized maximum values are all unity, to get frequency modulated (FM) part of the signal; (4) determine the amplitude modulated (AM) part of the signal by the term by term division of the original IMF series and FM signal. The combination of this iterative process of normalization and application of the Hilbert transform to the empirical AM signal is called the normalized Hilbert transform (NHT) method and the use of inverse cosine instead of inverse tangent in the computation of phase angles make the scheme 'direct quadrature (DQ)'. A detailed procedure of the same can be found in Huang et al. (2009b). The CEEMDAN-NHT (with direct quadrature) combination is adopted in this study to perform spectral analysis of streamflow and TSS concentration time series.

\section{Statistical significance test of IMF components}

Statistical significance test of IMF components (Wu and Huang 2005b) is a useful method for detecting whether an IMF obtained is a true signal or just a white noise component. The information obtained can be used for forecasting of the time series by incorporating the nonstationarity into account. The test is based on the postulate that the summation of logarithmic values of mean normalized energy and mean period of an IMF is zero. This test compares the spectral energy and the mean period relation between the IMFs of original signal and white noise. If the IMF energy of the observed data with a certain mean period is located above the confidence level, the corresponding IMF is considered as statistically significant at the given level. Basically it involves the following steps: (1) the computation of energy density of IMFs and its normalization by considering first IMF as the reference IMF; (2) generation of white noise series by Monte Carlo simulations, its EMD and computation of the 'spread function'; (3) estimation of the confidence band of spread function of white noise at a selected significance level, based on step (2). Then the points having coordinates of mean normalized energy and mean period of IMFs are located in the 2D plane. This enables a comparison of the energy level of different IMFs with the spread function of white noise. The IMFs of original time series $X(t)$ that have their energy densities located above the upper confidence line of the white noise series can be considered as 'true IMF' (free from white noise and contain information) and considered to be statistically significant at the selected confidence level. More details of the test can be found elsewhere (Wu and Huang 2004, 2005b).

\section{Time dependent intrinsic correlation analysis based on CEEMDAN}

Since most of the hydro-climatic time series possess multiscaling behavior, a scale dependent correlation analysis is more appropriate to establish the link between meteorological variables and hydrological variables (Papadimitriou et al. 2006; Rodo and Rodriguez-Arias 2006). But the selection of appropriate window size is a challenging problem while applying such techniques. Chen et al. (2010b) proposed a method for determining scale dependent correlation between two time series, namely time dependent intrinsic correlation (TDIC). This method employs the use of EMD (or its variants) to decompose both of the time series data into multiple time scales. It is to be noted that in this method the window size is fixed adaptively (based on properties of data), keeping the stationarity property of the data within the window and more importantly, the size of sliding window is fixed based on the instantaneous period (computed from instantaneous frequencies obtained by HT of IMFs). The different steps involved in TDIC analysis are:

1. Use CEEMDAN algorithm to decompose the two time series of interest into different time scales.

2. Compare the periodicities of IMFs of both series and select those IMFs with nearly same mean periodicity.

3. Find the instantaneous periods of both of the IMFs by HT.

4. Find the minimum sliding window size $\left(t_{d}\right)$ as maximum instantaneous period between 
the two signals at the current position $t_{k}$, i.e., $t_{d}=$ $\max \left(T_{1, i}\left(t_{k}\right), T_{2, i}\left(t_{k}\right)\right)$, where $T_{1, i}$ and $T_{2, i}$ are instantaneous periods.

5. Fix the sliding window as $t_{w}^{n}=\left[t_{k}-\frac{n t_{d}}{2}: t_{k}+\frac{n t_{d}}{2}\right]$, where $n$ is any positive number (a multiplication factor for minimum sliding window size). In this study, $n$ is selected as 1 considering the suggestions from past studies (Huang and Schmitt 2014).

6. Let IMF1 and IMF2 are two IMFs of nearly same mean period pertaining to two different time series. The TDIC of the pair of IMFs can be found out as, $R_{i}\left(t_{k}^{n}\right)=\operatorname{Corr}\left(I M F_{1, i}\left(t_{w}^{n}, I M F_{2, i}\left(t_{w}^{n}\right)\right)\right.$ at any $t_{k}$ where Corr is the correlation coefficient of two time series.

7. Perform student $t$-test to investigate whether the difference between the correlation coefficient $R_{i}\left(t_{k}^{n}\right)$ and zero is statistically significant or not.

8. Repeat steps $4-7$ iteratively till the boundary of the sliding window crosses the end points of the time series.

After computing the TDIC matrix, the TDIC plot is prepared. The horizontal axis of the TDIC plot is the time of the series (corresponding to the center position of the sliding window) and the vertical axis is the size of the sliding window. The TDIC plot will be triangular in shape and the correlation at the apex point will be the general correlation coefficient between the series considering the entire data length, if the maximum size of sliding window is fixed as the data length (Chen et al. 2010b). In general, half of the data length is selected as the maximum size of sliding window. The bottom contour of the triangular plots depicts the instantaneous frequency and hence a shift of the plots to larger time scales can be noticed in higher order IMFs (i.e., low frequency modes). The blank spaces in the plot (if present) represents that such correlations fail to satisfy the students $t$ test and hence not statistically significant. Recently, few researchers have successfully used this method for analyzing the correlation between different time series in marine environment (Huang and Schmitt 2014; Ismail et al. 2015; Derot et al. 2016); and for analyzing the hydro-climatic teleconnections of Indian summer monsoon rainfall (Adarsh and Janga Reddy 2016).

\section{Study area and data details}

Mahanadi river is one of the important intermittent river in India, in which one of the major multi-purpose reservoir project Hirakud is located. Mahanadi river has a length of

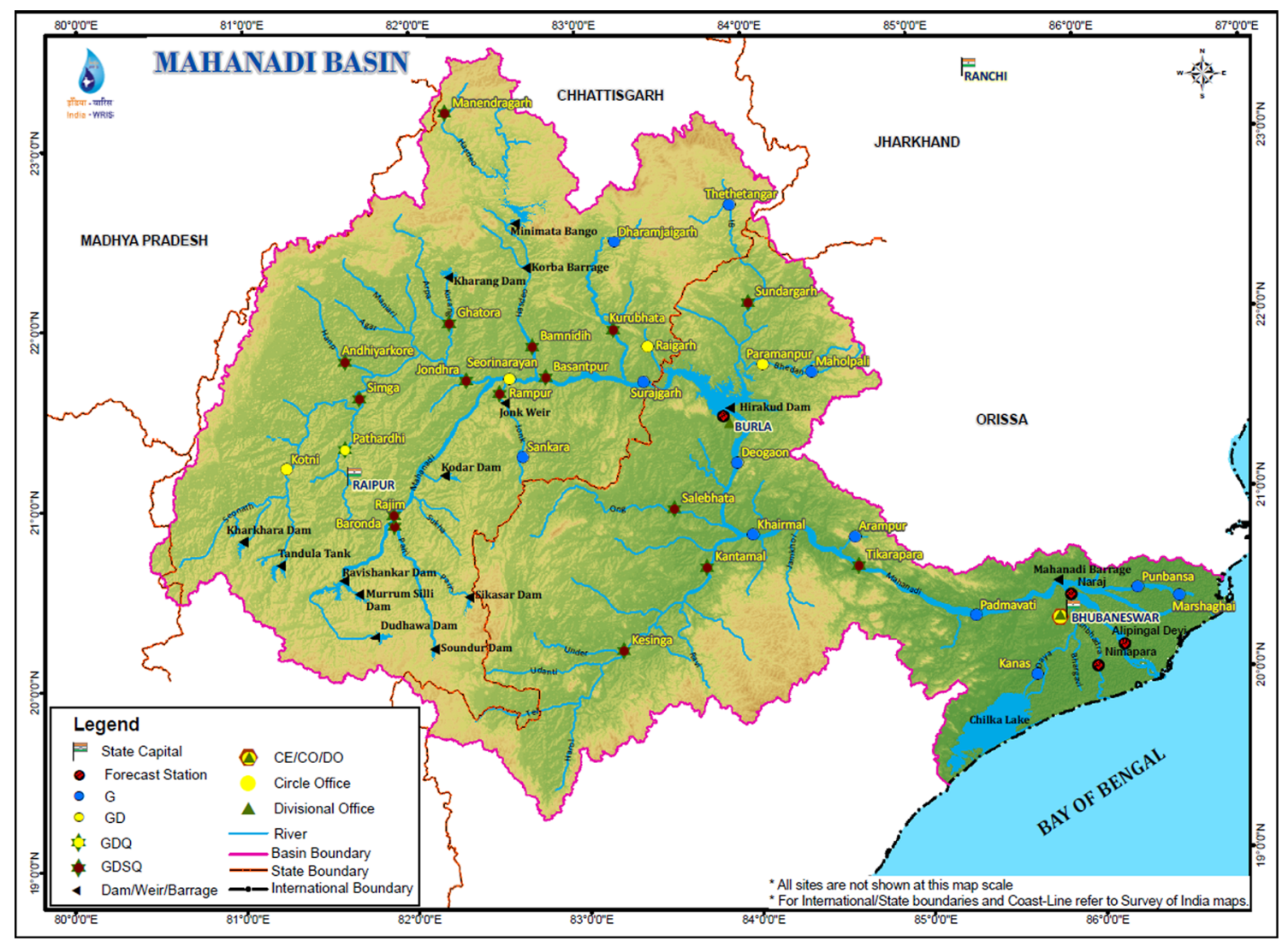

Fig. 1 Location map of Mahanadi basin (Source: http://india-wris.nrsc.gov.in/wrpinfo/index.php?title=Mahanadi) 

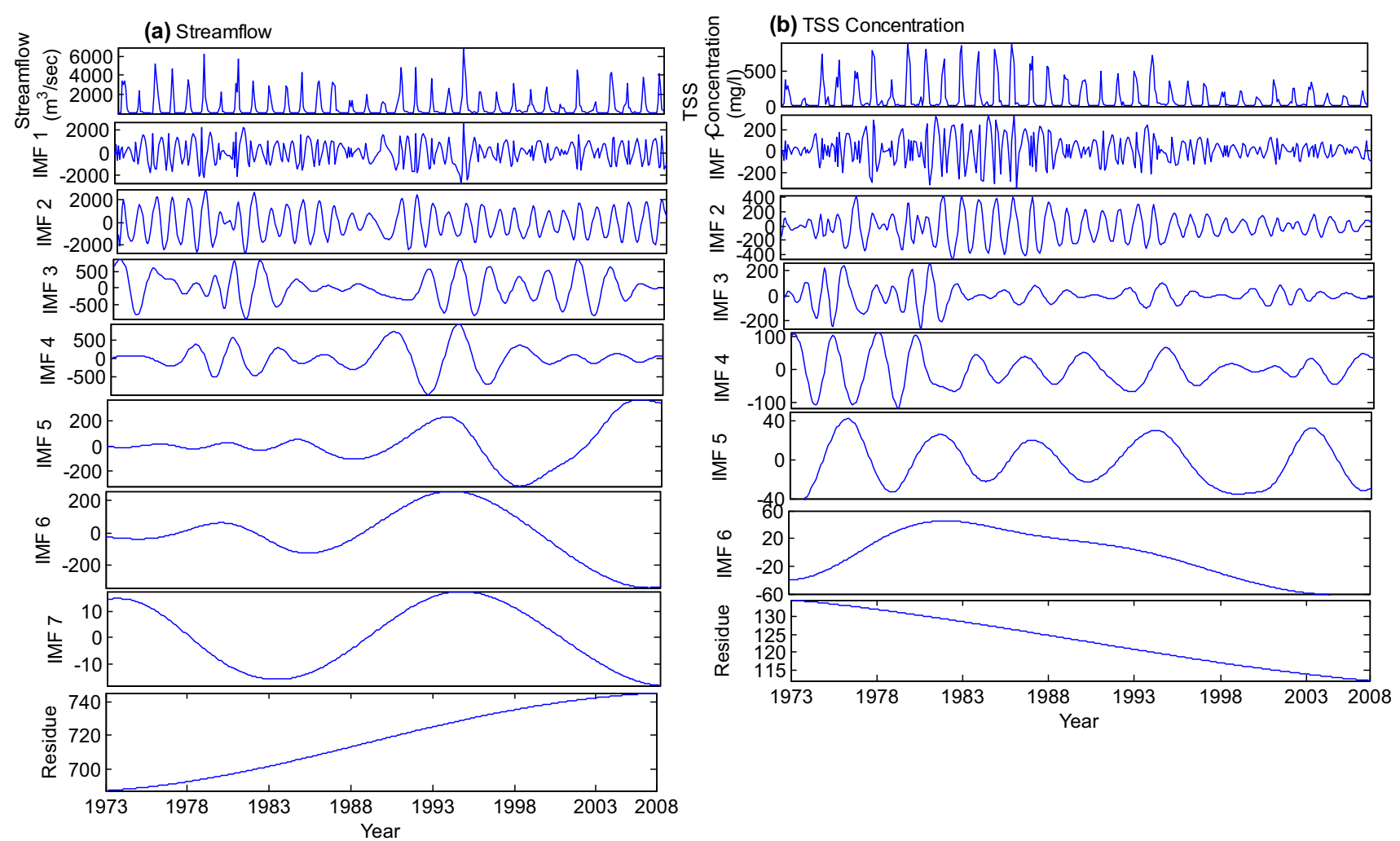

Fig. 2 Decomposition of monthly time series of a streamflow and b TSS concentration at Basantpur station

(a) Streamflow

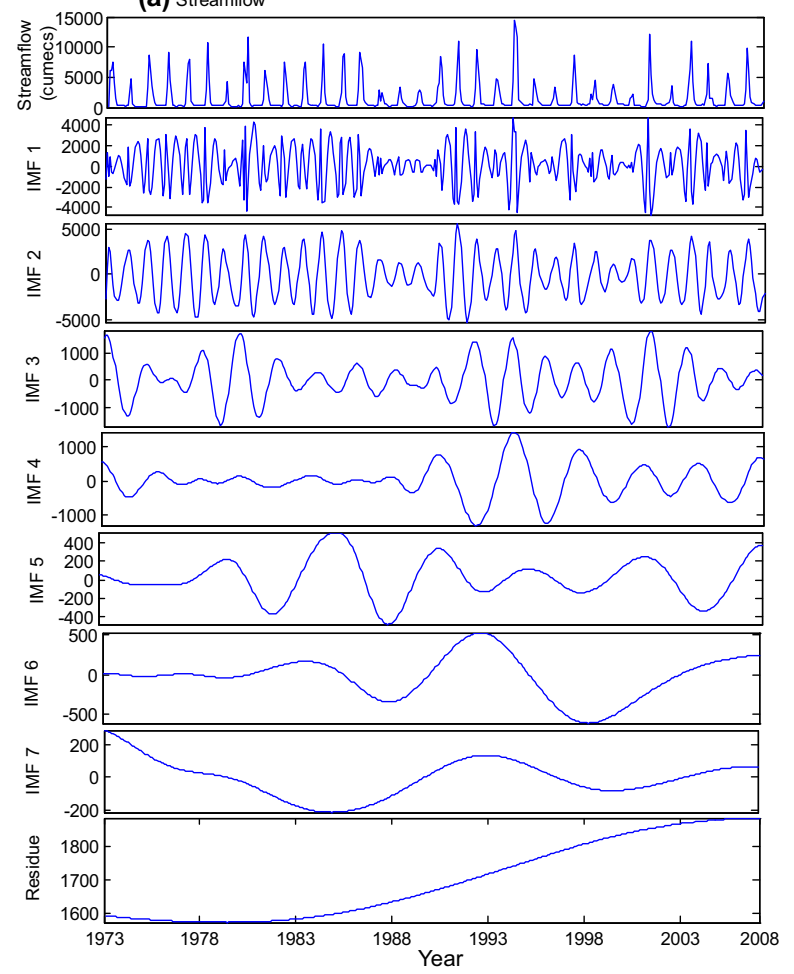

(b) TSS Concentration

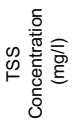

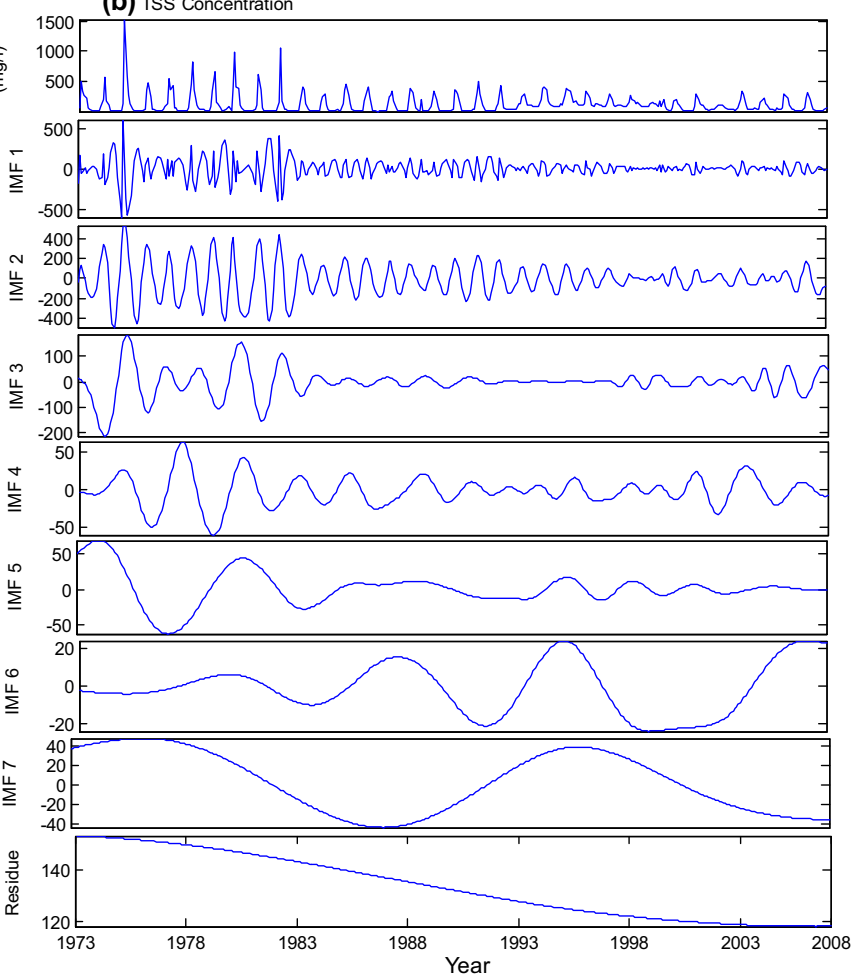

Fig. 3 Decomposition of monthly time series of a streamflow and $\mathbf{b}$ TSS concentration at Tikrapara station 
$850 \mathrm{~km}$ approximately rises in the highlands of Chattisgarh and flows through Chattisgarh and Orissa states in eastcentral India drains an area of $141,589 \mathrm{~km}^{2}$ to discharge into the Bay of Bengal along the east coast of India. The major part of the upper reaches of the Mahanadi river catchment encompasses most of the areas of Chhattisgarh state. Basantpur river gauging station in Mahanadi river is operated by the Central Water Commission (CWC) of India is located at few kilometres upstream of the Hirakud dam, the most important and largest among different control structures of the basin and the upper Mahanadi cover $60 \%$ of the Basin nearly $83,000 \mathrm{~km}^{2}$ of basin area. Tikrapara station is located in the central Mahanadi basin (located in Orissa state between $82^{\circ} \mathrm{E} 19^{\circ} \mathrm{N}$ and $86^{\circ} \mathrm{E} 22^{\circ} \mathrm{N}$ having area of nearly $43,000 \mathrm{~km}^{2}$ ). Better understanding of the dynamic processes of sediment transport and water discharge needs more detailed datasets, such as monthly data (Walling and Fang 2003; Zhang et al. 2009). Daily records of streamflow and total suspended sediment concentration at Basantpur and that at Tikrapara for the period 1973-2007 are collected from Central Water Commission (http://www.india-wris.nrsc.gov.in/) and are converted to monthly data for the present study. The location map showing the Basantpur and Tikrapara stations and Hirakud dam are shown in Fig. 1.

\section{Results and discussion}

In the following, first the results of multiscale decomposition of streamflow (SF) and TSS concentration time series employing the CEEMDAN algorithm are presented. Subsequently, the results of Hilbert spectral analysis of IMF components of both the series obtained from the decomposition are presented. Then the results of correlation and TDIC analyses of IMFs of streamflow and sediment concentration data from both the stations are presented, and supported by appropriate interpretations and discussion.

\section{Multiscale spectral analysis of streamflow and suspended sediment concentration series}

The CEEMDAN method is applied upon the monthly SF and TSS concentration time series by using a noise standard deviation of 0.2 and total of 500 realizations to get the ensemble of modes (Torres et al. 2011; Antico et al. 2014). The decomposition resulted in six IMFs and a residue for both the series, which is generally less than the maximum number expected $\log _{2}(L)$ (Flandrin and Gonçalvès 2004; Fladrin et al. 2004), where $L$ is the length of the dataset. The modes obtained for streamflow and TSS concentration are presented in Fig. 2 and Fig. 3, respectively for

Table 1 Mean periods and percentage variability explained by different IMFs obtained for streamflow and TSS concentration data from Basantpur and Tikrapara stations

\begin{tabular}{|c|c|c|c|c|c|c|}
\hline \multirow[t]{2}{*}{ Mode } & \multicolumn{3}{|c|}{ Streamflow } & \multicolumn{3}{|c|}{ TSS concentration } \\
\hline & $\mathrm{R}$ & Mean period (month) & $\%$ Variability explained & $\mathrm{R}$ & Mean period (month) & $\%$ Variability explained \\
\hline \multicolumn{7}{|l|}{ (a) Basantpur } \\
\hline IMF1 & 0.250 & 5.771 & 32.713 & 4.810 & 0.265 & 24.843 \\
\hline IMF2 & 0.662 & 11.882 & 54.713 & 10.359 & 0.676 & 57.605 \\
\hline IMF3 & 0.193 & 22.444 & 6.540 & 17.565 & 0.289 & 10.072 \\
\hline IMF4 & 0.154 & 36.727 & 4.080 & 33.667 & 0.131 & 4.149 \\
\hline IMF5 & 0.086 & 80.800 & 0.978 & 80.800 & 0.120 & 0.987 \\
\hline IMF6 & 0.005 & 202.000 & 0.956 & 404.000 & 0.209 & 2.255 \\
\hline IMF7/Residue & 0.025 & 202.000 & 0.005 & 404.00 & 0.161 & 0.090 \\
\hline $\begin{array}{l}\text { Residue } \\
\text { (b) Tikrapara }\end{array}$ & -0.011 & 404.000 & 0.014 & & & \\
\hline IMF1 & 0.276 & 5.527 & 32.374 & 0.232 & 4.756 & 31.224 \\
\hline IMF2 & 0.675 & 12.029 & 58.451 & 0.683 & 10.487 & 57.982 \\
\hline IMF3 & 0.228 & 20.450 & 5.545 & 0.142 & 16.360 & 6.088 \\
\hline IMF4 & 0.165 & 31.462 & 2.251 & 0.076 & 25.563 & 0.805 \\
\hline IMF5 & 0.074 & 58.429 & 0.447 & 0.052 & 45.444 & 1.197 \\
\hline IMF6 & 0.110 & 102.250 & 0.682 & 0.063 & 102.250 & 0.386 \\
\hline IMF7 & 0.055 & 204.500 & 0.122 & 0.166 & 204.500 & 2.021 \\
\hline Residue & -0.018 & 409.00 & 0.127 & 0.097 & 409.000 & 0.297 \\
\hline
\end{tabular}


Basantpur and Tikrapara stations. The mean period of IMFs are computed by the zero-crossing method (by counting the number of extrema and hence zero crossing) (Barnhart and Eichinger 2011). The mean period of the streamflow and sediment concentration of Basantpur and Tikrapara stations are presented in Table 1. It is also noticed that the annual mode (IMF2) is showing the highest correlation with the respective series for all cases. From the nature of residue, it is noted that both the streamflow and TSS concentration show opposing trend for both the stations during the study period (1973-2007).

Next, the statistical significance test of IMF components of streamflow and TSS concentration data from both stations is performed and the results are presented in Fig. 4. From Fig. 4, it is clear that the annual cycle (IMF2) is significant in all the four time series. In the streamflow and TSS concentration time series, short term interannual cycles up to 3 years (IMF3 and IMF4) are significant. But in the streamflow variability of Tikrapara station, none of the IMFs other than annual cycle (IMF2) is found to be significant and for TSS series also the energy level of IMF4 and IMF6 is relatively less for the Tikrapara station when compared with that of Basantpur station. This may be attributed to the fact that the station is located at far downstream of the major control structure-the Hirakud dam and human interventions are more influential in the hydrologic time series of the Tikrapara station.

Further, the obtained IMFs are subjected to the NHT to get the instantaneous amplitudes and frequencies. The Hilbert spectral representations of different IMFs are presented in Figs. 5 and 6, respectively for the data from Basantpur station and Tikrapara station. From the spectral representation of different data (Fig. 5 and Fig. 6) some common features can be identified. All the time series shows more intermittency in IMF1 ( 5-6 month periodicity). The highest amplitudes of high frequency modes are found to be localized in time. The dominant frequency for different IMFs (at which there is a concentration of higher amplitudes) is found to be occurring at different time instant, i.e., dominant frequency is time varying in characteristics. This time varying property of sediment concentration time series was also reported by $\mathrm{Cao}$ et al. (2007) and Kuai and Tsai (2012) in earlier studies. The basic statistical properties (maximum, minimum, mean and (a) Basantpur- Streamflow

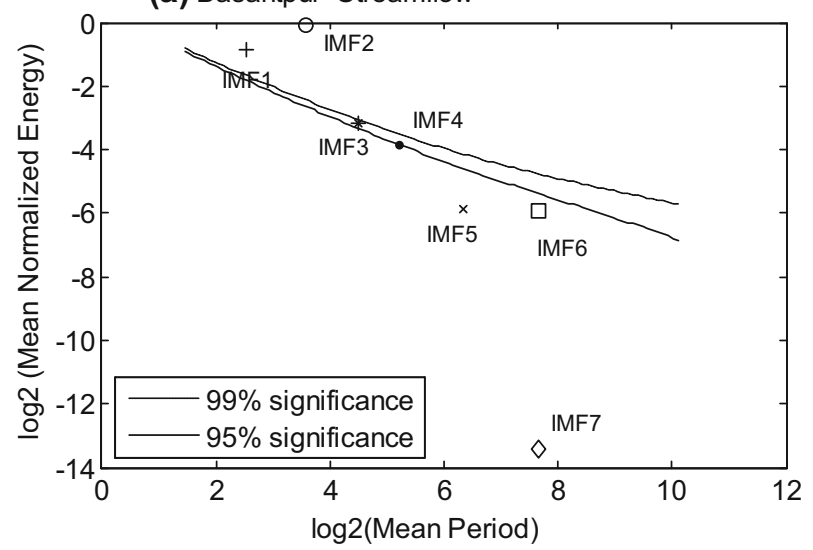

(c) Tikrapara- Streamflow

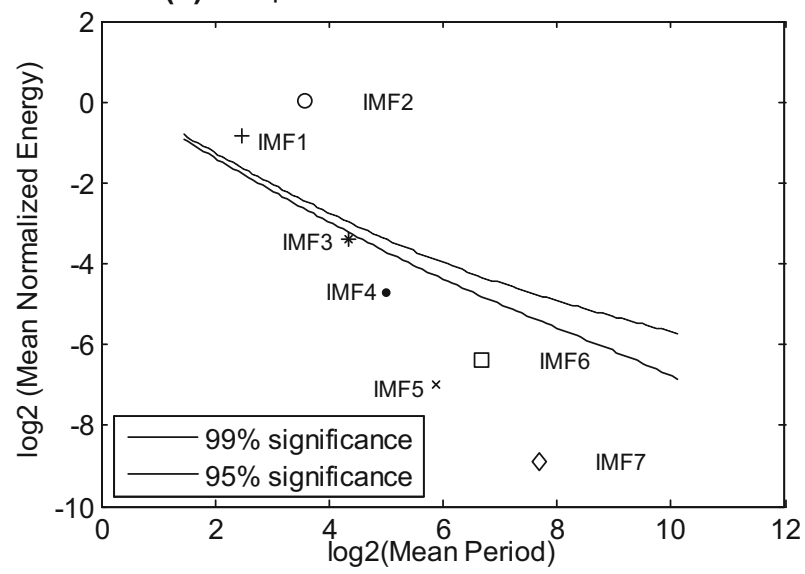

(b) Basantpur- TSS Concentration

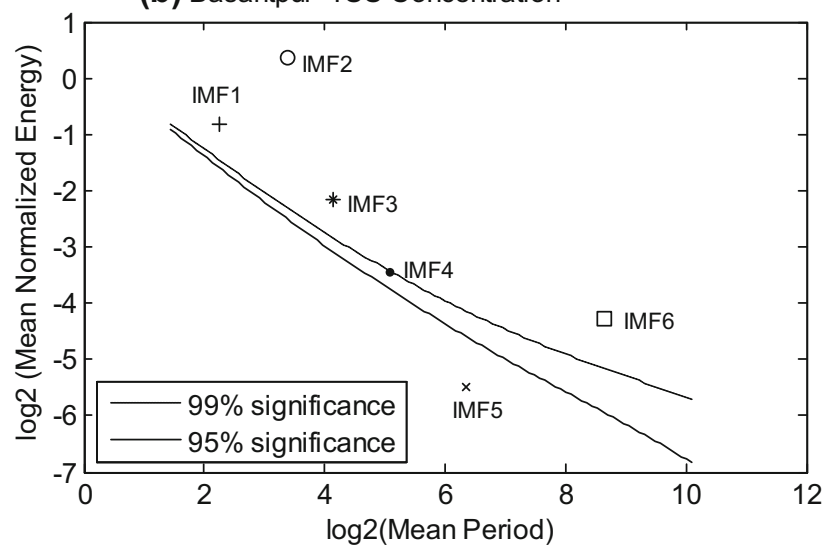

(d) Tikrapara- TSS Concentration

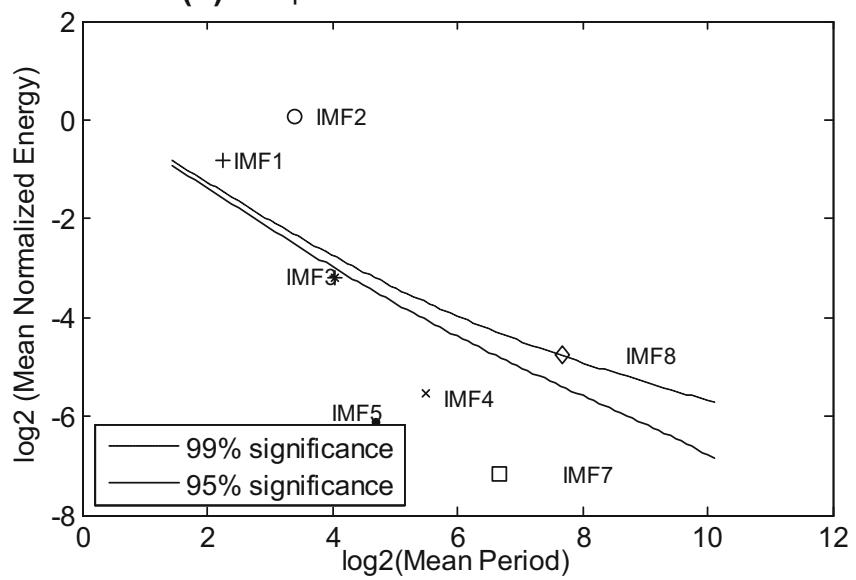

Fig. 4 Statistical significance test of IMF components of streamflow and TSS concentration from Basantpur and Tikrapara stations (Upper curve for $99 \%$ significance and lower curve for $95 \%$ significance) 
standard deviation) of the instantaneous amplitude and instantaneous frequency of different series are presented in Table 2.

The mean instantaneous frequencies of first five IMFs of streamflow time series of Basantpur station are 0.166, $0.085,0.043,0.027$ and 0.012 ; and the corresponding mean period are $6.03,11.73,23.09,37.35,81.08$, which are quite similar to the periodicity based on zero crossing method, particularly for the lower modes. For the low frequency modes, the periodicity may differ from that obtained by zero crossing method and the 'dyadic' behavior of periodicity may not get preserved because of less number of cycles present in such modes. From Table 2, it is also noted that the highest variability in instantaneous frequency is for IMF1 (range 0-0.45 and standard deviation of 0.1 in all cases). This component shows high turbulence of instantaneous frequencies and it is responsible for non-linearity of the dataset, as noticed by Kuai and Tsai (2012) in a similar study. Also for all the four time series, the mean amplitude is maximum for IMF2, which denotes near annual periodicity.

(a) Basantpur-Streamflow

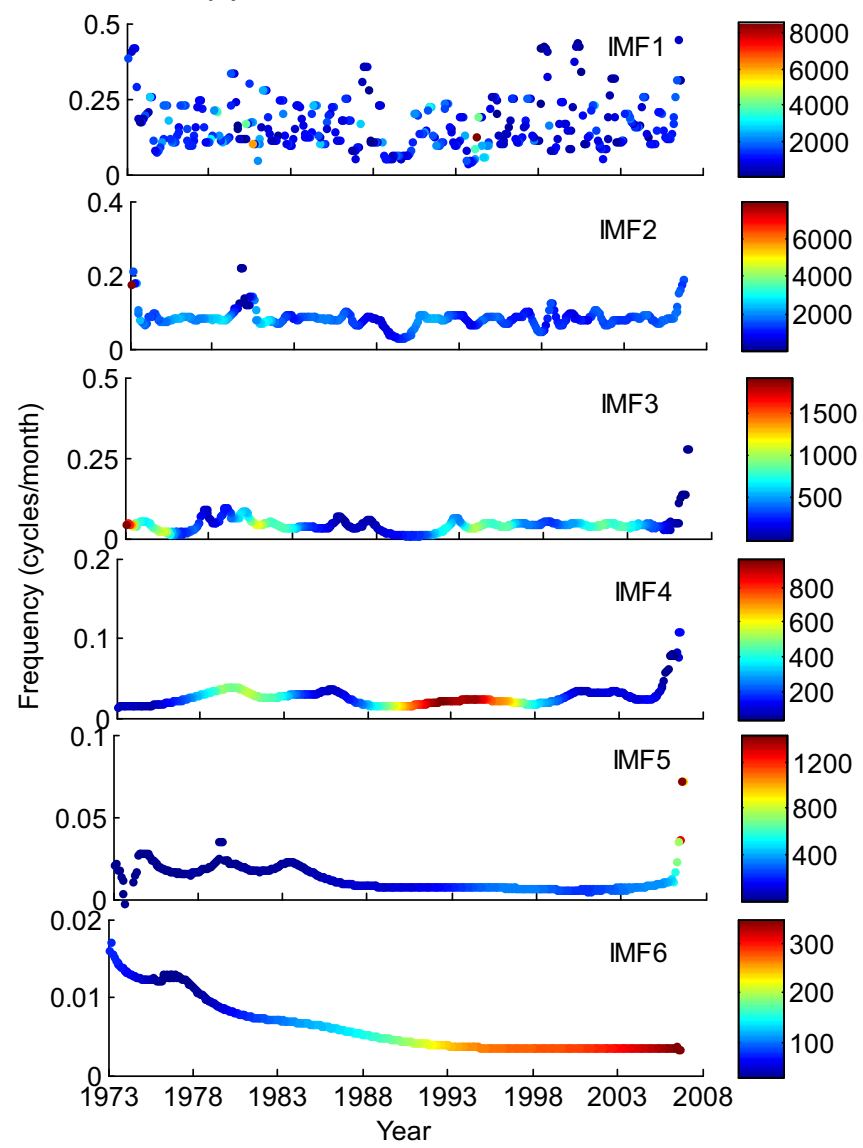

Further, the marginal spectrum of the four time series (streamflow and TSS concentration of both stations) are prepared and presented in Fig. 7. From the different panels of Fig. 7, it is noticed that both Fourier and Hilbert spectral analysis identified a prominent spectral period near annual scale ( $\sim 0.085$ months). Further it is noticed that for mean instantaneous frequencies between 0.012 and 0.085 months (corresponding to period of 7-1 year), the evolution of spectra are quite similar for streamflow and TSS concentration data of Basantpur station. This could be referred as climatic regime where inter annual climate oscillations may influence the variability of streamflow (Thompson and Katul 2012). Hence this could be possibly linked with the large scale climatic oscillations operating at that scales which control the variability of streamflow and TSS concentrations of Mahanadi basin. Gadgil et al. (2004) highlighted that two such large scale circulation patterns from Pacific Ocean and tropical Indian Ocean (ENSO-EINiño Southern Oscillation, and EQUINOO-Equatorial Indian Ocean Oscillations) operating at similar scales significantly influence the precipitation processes in the Indian

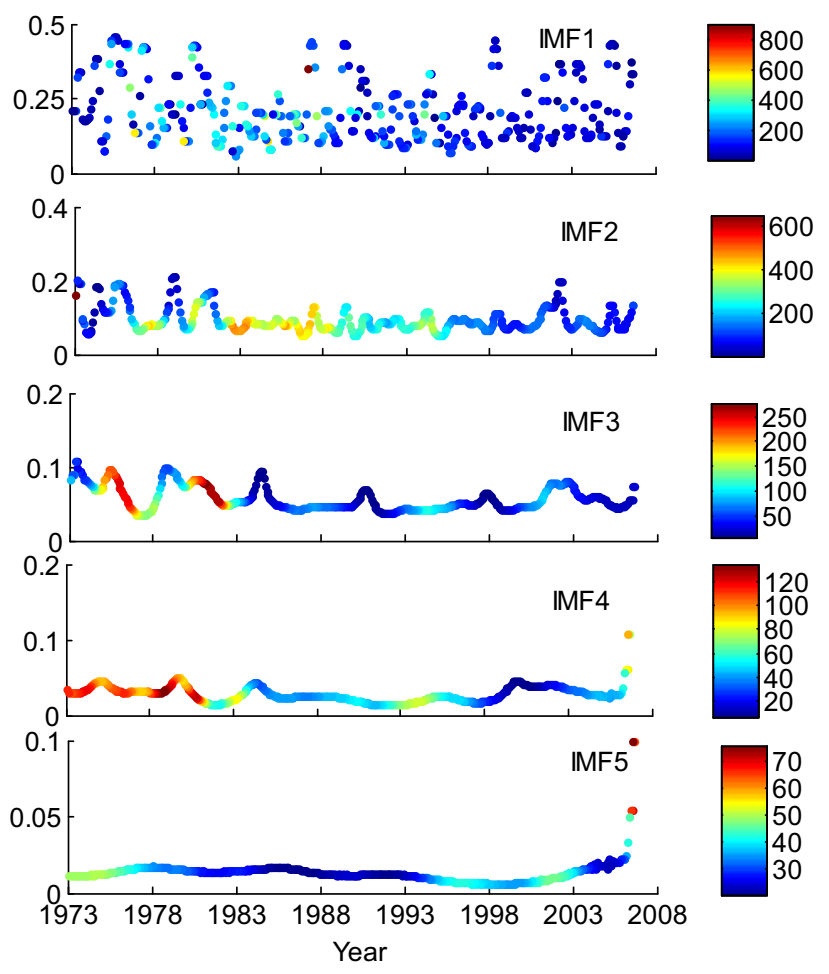

Fig. 5 Instantaneous frequency trajectories of a streamflow b TSS concentration data from Basantpur station 
Table 2 Statistical properties of instantaneous amplitudes and frequencies obtained by the HHT of streamflow and TSS concentration data from Basantpur and Tikrapara stations

\begin{tabular}{|c|c|c|c|c|c|c|c|c|}
\hline \multirow{2}{*}{$\begin{array}{l}\text { IMF } \\
\text { number }\end{array}$} & \multicolumn{4}{|c|}{ Instantaneous amplitude } & \multicolumn{4}{|c|}{ Instantaneous frequency } \\
\hline & Min A & $\operatorname{Max} A$ & $\mathrm{Mn} \mathrm{A}$ & Std A & Min F & Max F & Mn F & Std F \\
\hline \multicolumn{9}{|c|}{ (a) Streamflow-Basantpur } \\
\hline IMF1 & 85.79 & 8527.79 & 1246.79 & 808.48 & 0.000 & 0.446 & 0.166 & 0.090 \\
\hline IMF2 & 70.47 & 7963.33 & 1620.93 & 618.03 & 0.030 & 0.222 & 0.085 & 0.025 \\
\hline IMF3 & 0.78 & 1928.94 & 523.26 & 323.67 & 0.000 & 0.278 & 0.043 & 0.034 \\
\hline IMF4 & 43.86 & 963.33 & 370.79 & 276.87 & 0.014 & 0.108 & 0.027 & 0.012 \\
\hline IMF5 & 4.34 & 1434.28 & 180.46 & 178.37 & 0.001 & 0.072 & 0.012 & 0.008 \\
\hline IMF6 & 29.47 & 349.99 & 185.53 & 102.65 & 0.003 & 0.017 & 0.006 & 0.003 \\
\hline \multicolumn{9}{|c|}{ (b) TSS Concentration-Basantpur } \\
\hline IMF1 & 1.784 & 905.459 & 149.962 & 115.525 & 0.056 & 0.459 & 0.211 & 0.105 \\
\hline IMF2 & 5.178 & 652.430 & 224.069 & 123.787 & 0.051 & 0.213 & 0.096 & 0.035 \\
\hline IMF3 & 7.423 & 277.043 & 80.933 & 68.396 & 0.034 & 0.108 & 0.058 & 0.017 \\
\hline IMF4 & 6.711 & 134.572 & 60.246 & 32.894 & 0.014 & 0.109 & 0.029 & 0.011 \\
\hline IMF5 & 20.147 & 76.033 & 32.704 & 10.003 & 0.006 & 0.099 & 0.014 & 0.008 \\
\hline \multicolumn{9}{|c|}{ (c) Streamflow-Tikrapara } \\
\hline IMF1 & 19.285 & $13,384.565$ & 2433.710 & 1665.991 & 0.001 & 0.448 & 0.176 & 0.098 \\
\hline IMF2 & 740.935 & 6173.152 & 3337.220 & 1155.697 & 0.050 & 0.151 & 0.084 & 0.014 \\
\hline IMF3 & 45.193 & 2014.955 & 938.414 & 525.996 & 0.029 & 0.110 & 0.046 & 0.012 \\
\hline IMF4 & 35.466 & 1491.268 & 541.569 & 427.532 & 0.018 & 0.069 & 0.030 & 0.010 \\
\hline IMF5 & 57.326 & 581.123 & 269.319 & 150.178 & 0.010 & 0.022 & 0.014 & 0.003 \\
\hline \multicolumn{9}{|c|}{ (d) TSS Concentration-Tikrapara } \\
\hline IMF1 & 1.467 & 1078.307 & 134.688 & 143.152 & 0.001 & 0.473 & 0.201 & 0.102 \\
\hline IMF2 & 0.601 & 574.103 & 201.332 & 131.987 & 0.047 & 0.184 & 0.089 & 0.025 \\
\hline IMF3 & 1.310 & 251.329 & 54.739 & 59.791 & 0.023 & 0.194 & 0.056 & 0.022 \\
\hline IMF4 & 4.209 & 67.855 & 23.328 & 15.929 & 0.018 & 0.077 & 0.038 & 0.013 \\
\hline IMF5 & 3.769 & 79.270 & 25.604 & 21.998 & 0.007 & 0.032 & 0.016 & 0.008 \\
\hline IMF6 & 3.832 & 54.962 & 18.015 & 10.235 & 0.005 & 0.072 & 0.010 & 0.006 \\
\hline
\end{tabular}

subcontinent and Maity and Nagesh Kumar (2008) proved that such circulation patterns can influence the streamflow variability of Mahanadi basin. However a difference is noticed in the evolution of two spectra of Tikrapara station, which is located at far downstream of Hirakud reservoir. It is logical to ascertain that the streamflow and sediment concentrations of Basantpur are influenced more by such external forcings, while that at Tikrapara could also be influenced by internal factors like basin characteristics and human interventions.

\section{Investigating the association between streamflow and TSS time series using TDIC analysis}

A visual comparison of IMFs and the quantitative estimation of correlation between different IMFs enable us to find the association between the streamflow and TSS concentration time series at different scales over different time spells. Therefore, first a plot of IMFs and residue of both streamflow and TSS concentration time series from
Basantpur station are made and presented in Fig. 8. A careful perusal of the plots of IMFs (Fig. 8) shows that during most of the time periods, the evolution of IMFs of TSS matches well with that of streamflow, particularly in high frequency modes. It is noticed that a strong direct inphase relation exists between the annual modes of streamflow and TSS concentration. However, in some of the time spells, weak relationship between the IMFs are also noticed (for e.g., till 1990s in IMF5, before 1980s in IMF4). The trend component (residue) is a slowly varying climate mode, which delineates the progressive change from below to above average streamflow (or TSS). From Fig. 8, it is also noticed that the temporal evolution of trend (i.e., how the trend changes over and below the zero mean) components of streamflow and TSS concentration are similar for most of the periods and the zero crossing is happening nearly at the year 1990 . The plots of the modes of streamflow and TSS concentration time series from Tikrapara station is also made and presented in Fig. 9. Here also in the high frequency IMFs, there is an in-phase 
(a) Tikrapara- Streamflow

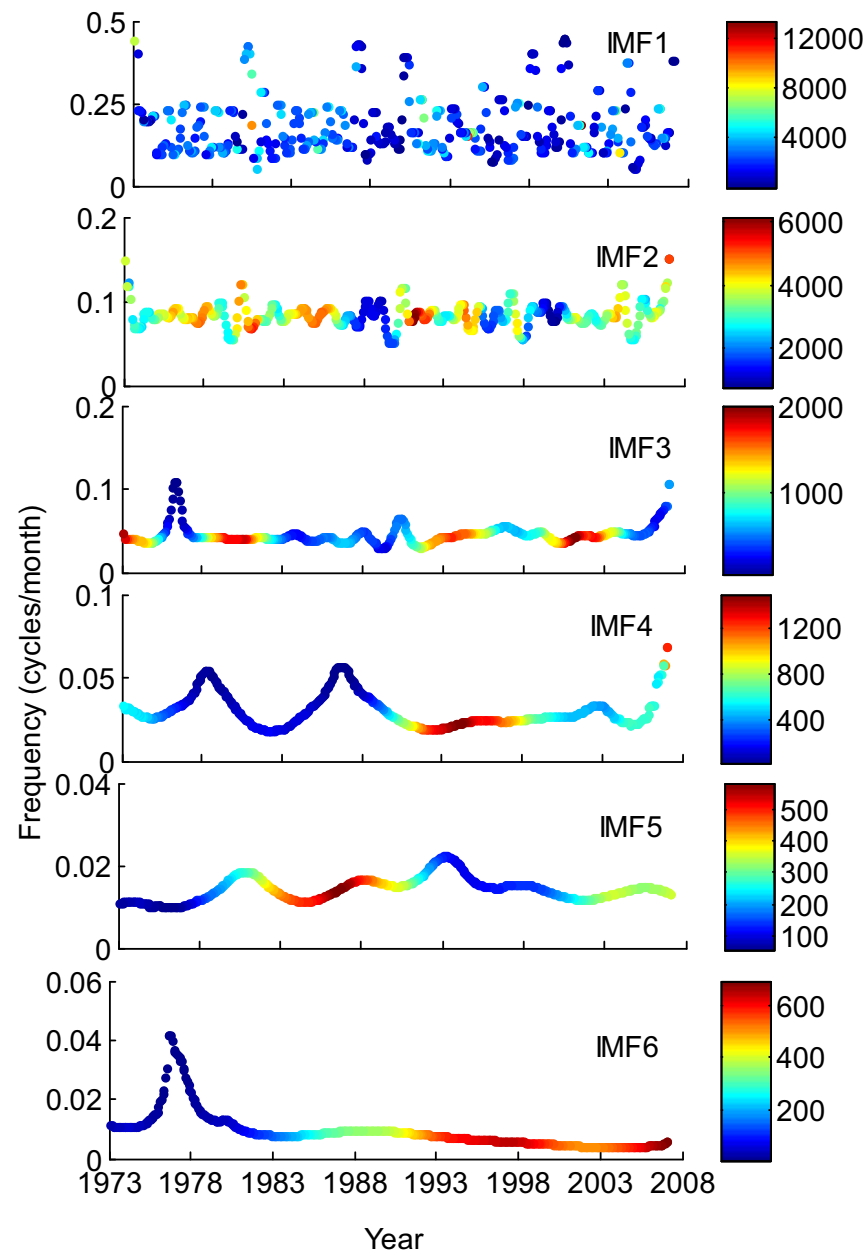

(b) Tikrapara- TSS Concentration

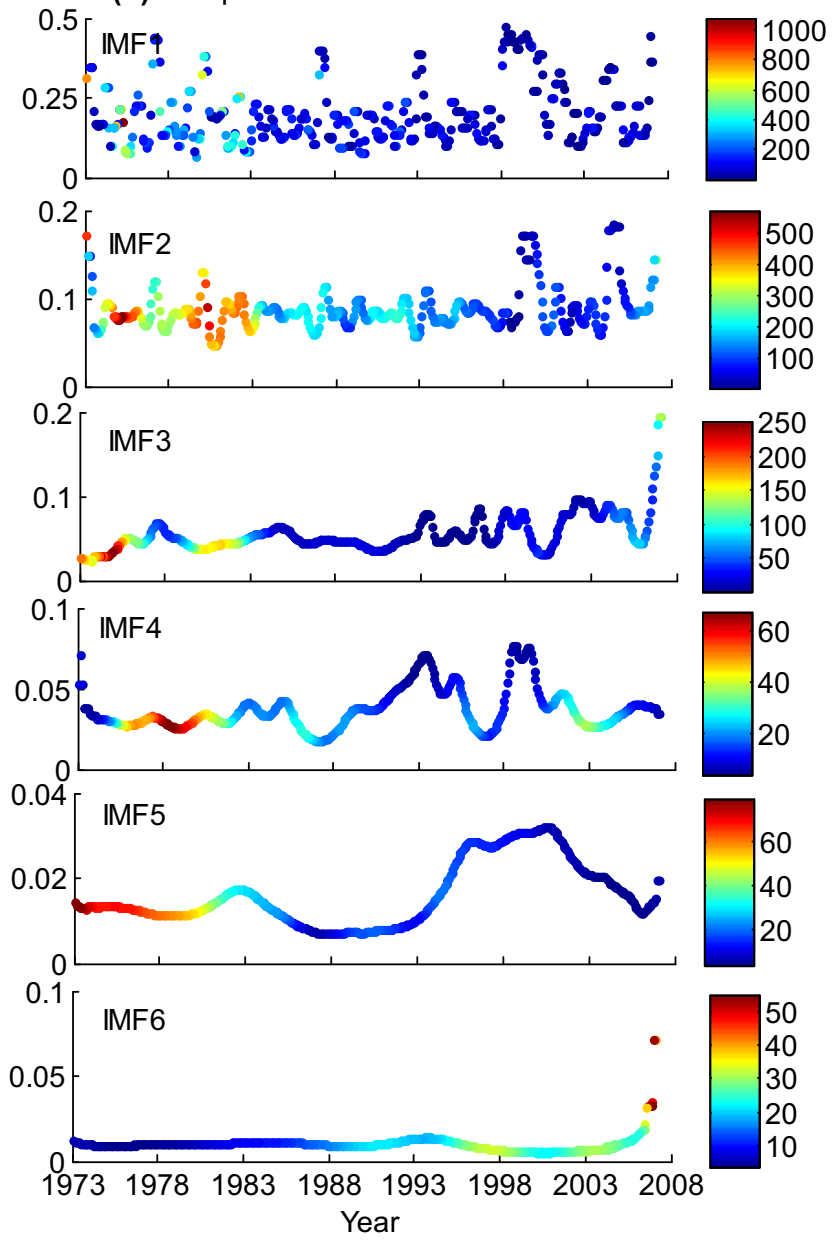

Fig. 6 Instantaneous frequency trajectories of a streamflow b TSS concentration data from Tikrapara station

relation between the two but in the low frequency modes (IMF3-IMF5) there is a clear dominancy of anti-phase (negative) relation between streamflow and TSS in the time domain.

To quantitatively ascertain the association between streamflow and TSS concentration, first the overall correlation between the TSS and streamflow data is computed and it is found to be 0.76 at Basantpur station and 0.69 at Tikrapara station. But these values only give a linear association between the two time series, which alone is not sufficient to find the true association between two non-linear and nonstationary time series. A detailed cross correlation analysis is made between the modes of streamflow and that of TSS concentration series of both Basantpur and Tikrapara station and the results are presented in Table 3 .

From Table 3 it is noted that there exists strong positive association between corresponding IMFs of the series (between IMF1 of streamflow and that of TSS, IMF2 of streamflow and that of TSS, etc.), but there exists a strong negative correlation between the two $(-0.99)$ for the residue. Also, the IMF1 of TSS is negatively correlated with the rest of the IMFs of streamflow. Similar observation can be made for other IMFs also. Similarly, strong positive correlation between the respective modes is noticed for all modes except IMF4 and the residue in the decomposition of data from Tikrapara station. Therefore, the possibility of a reversal in the nature of association between the two series in different scales cannot be ignored. In other words, in some time scale the positive correlation between the two series may prevail, but in some other scale the correlation can be negative. The negative correlation between sediment load and streamflow on longer time scales confirm the general trend of sediment load and streamflow (Zhang et al. 2009). Also, it is to be noted that the above cross correlation analysis is done by considering the entire time span. Based on the comparison of different IMFs (Figs. 8, 9), it can be inferred that if shorter time spells are considered, an opposing nature of correlation may exists between streamflow and TSS irrespective of the nature of overall correlation between 

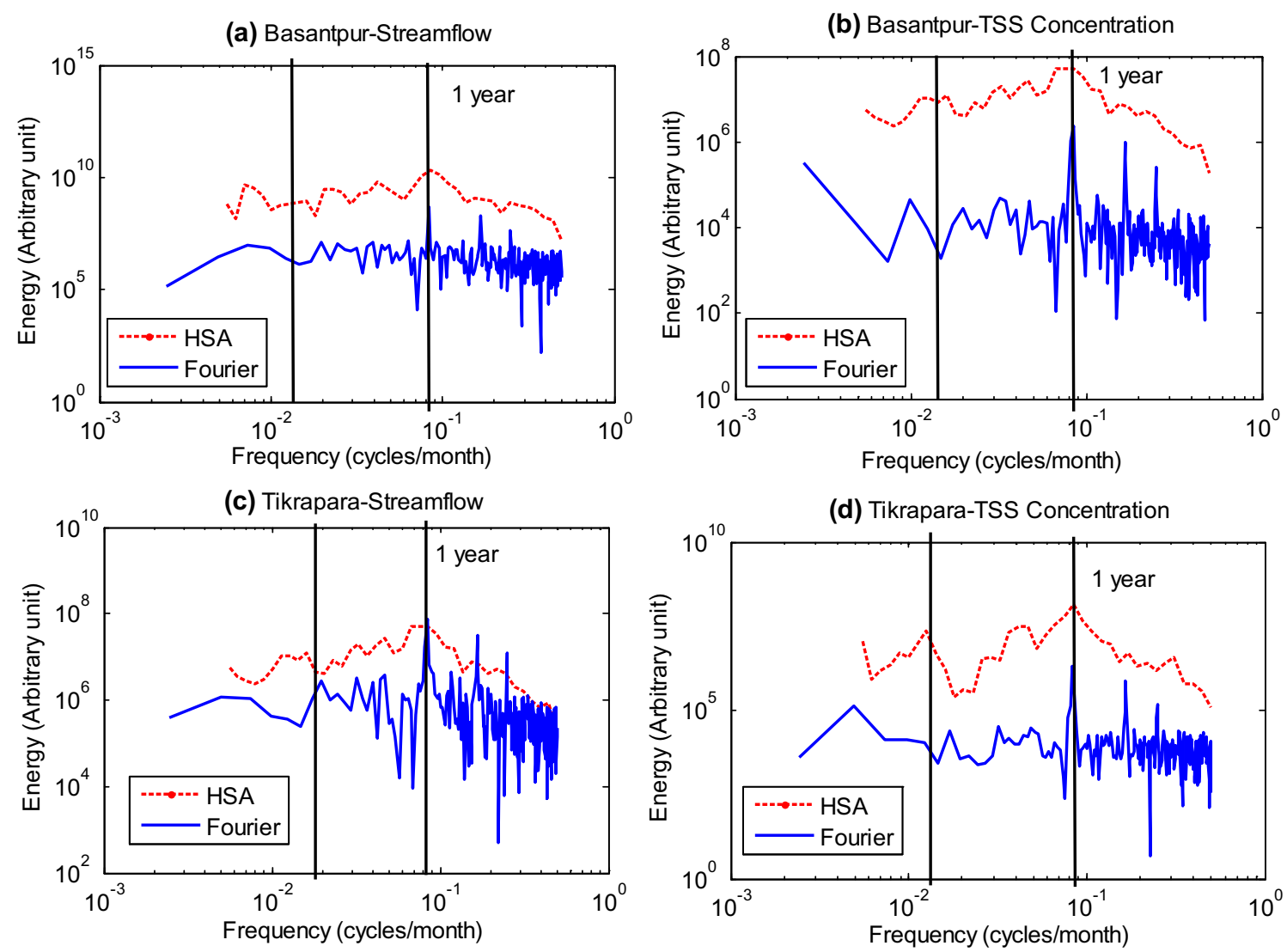

Fig. 7 Marginal Hilbert and Fourier spectrum for streamflow and TSS concentration. a, b For data from Basantpur staton; c, d For data from Tikrapara station. The right vertical bar refer annual time scale while the left vertical bar refer the inter-annual time scale
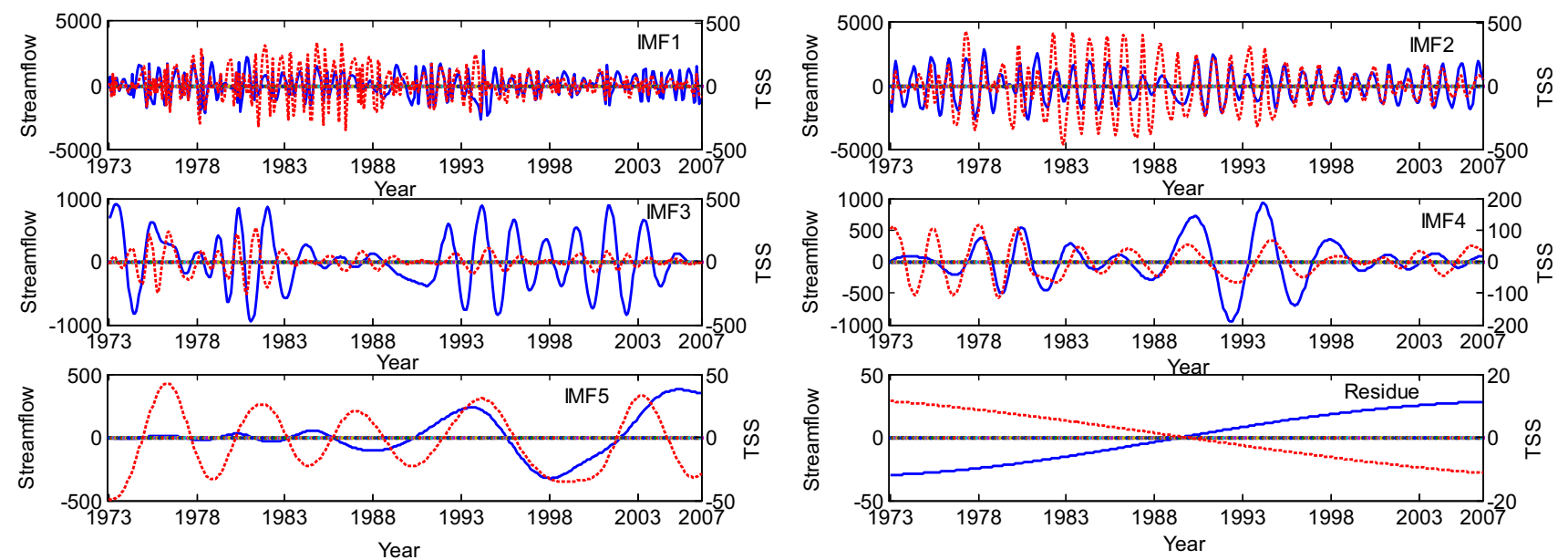

Fig. 8 Comparison of first five IMFs and the residue of streamflow with that of TSS concentration time series of Basantpur station. The solid line (blue) represents the orthogonal mode of streamflow time series and dotted line (red) represents the orthogonal mode of TSS concentration series

different IMFs. Also overall small correlation between streamflow and sediment at certain time scales (for example, IMF3 in Basantpur station and IMF4 in Tikrapara station) might be because of the existence of such opposing correlations for shorter time spells. Such opposing nature of correlation may nullify the association and finally lead to the quite less magnitude for the overall correlation in that time scale. Hence it is very important to identify the period of existence of such unusual negative (positive) correlation between the two and the periodic time scale at which such 
Table 3 Correlation coefficients between modes of streamflow and TSS concentration at Basantpur station and Tikarapara station

\begin{tabular}{lrrrrrrrr}
\hline TSS Concentration & \multicolumn{2}{l}{ Streamflow } \\
\cline { 2 - 9 } & \multicolumn{1}{l}{ IMF1 } & \multicolumn{1}{c}{ IMF2 } & IMF3 & IMF4 & IMF5 & IMF6 & IMF7 & Residue \\
\hline (a) Basantpur & & & & & & & & \\
IMF1 & $\mathbf{0 . 5 2 4}$ & -0.258 & 0.033 & 0.006 & -0.033 & -0.007 & -0.042 & -0.047 \\
IMF2 & -0.135 & $\mathbf{0 . 6 4 8}$ & 0.016 & -0.038 & 0.016 & -0.025 & -0.005 & 0.028 \\
IMF3 & -0.196 & 0.390 & 0.076 & 0.002 & 0.005 & 0.004 & 0.013 & 0.011 \\
IMF4 & -0.064 & 0.016 & 0.180 & $\mathbf{0 . 5 5 0}$ & 0.026 & -0.082 & -0.010 & 0.004 \\
IMF5 & -0.025 & 0.012 & 0.034 & -0.128 & $\mathbf{0 . 3 2 7}$ & 0.076 & -0.038 & -0.093 \\
IMF6 & -0.009 & -0.009 & -0.069 & -0.018 & -0.185 & $\mathbf{0 . 4 3 1}$ & -0.174 & $-\mathbf{0 . 6 3 6}$ \\
Residue & 0.015 & -0.021 & 0.087 & -0.008 & -0.187 & 0.242 & 0.072 & $-\mathbf{0 . 9 9 9}$ \\
(b) Tikrapara & & & & & & & & \\
IMF1 & $\mathbf{0 . 5 5 8}$ & $-\mathbf{0 . 3 5 4}$ & -0.019 & -0.017 & -0.011 & 0.028 & 0.024 & 0.028 \\
IMF2 & $-\mathbf{0 . 2 7 0}$ & $\mathbf{0 . 7 7 4}$ & 0.026 & 0.035 & -0.012 & -0.035 & 0.003 & 0.018 \\
IMF3 & -0.052 & 0.023 & $\mathbf{0 . 3 0 0}$ & $\mathbf{0 . 2 2 9}$ & 0.000 & 0.015 & 0.014 & 0.022 \\
IMF4 & 0.008 & -0.003 & 0.069 & 0.019 & -0.001 & 0.062 & -0.013 & -0.011 \\
IMF5 & 0.014 & 0.005 & 0.031 & -0.044 & -0.038 & -0.125 & -0.057 & 0.000 \\
IMF6 & 0.016 & -0.021 & 0.005 & 0.044 & -0.128 & $\mathbf{0 . 2 0 0}$ & -0.083 & 0.146 \\
IMF7 & -0.051 & 0.006 & -0.128 & 0.042 & 0.213 & 0.109 & $\mathbf{0 . 5 5 6}$ & 0.060 \\
Residue & -0.007 & 0.028 & 0.056 & 0.042 & -0.058 & -0.045 & -0.264 & $-\mathbf{0 . 9 5 1}$ \\
\hline
\end{tabular}

Bold numbers indicates significant correlation at $5 \%$ significance level correlation exist. To get information on such local association between the two series and the strength of the association, a running correlation analysis framed upon sliding windows is to be used. The HHT based TDIC analysis is one such multiscale running correlation analysis, which is helpful to get such information on local correlations. So the TDIC analysis is performed between the IMFs of streamflow and TSS concentration with comparable periodicities. The TDIC plots are prepared for different IMFs and presented in Figs. 10 and 11, respectively for Basantpur and Tikrapara stations.

The TDIC analysis between streamflow and TSS concentration in Basantpur station showed a dominancy of strong long range positive correlation in IMF1, IMF2 and IMF4. However, in IMF3 and IMF5 a negative association between the two is noticed during $\sim 1980-1990$ period. More importantly, in the above mode, the nature of association changes over the time domain. i.e., there are frequent reversals of correlation from positive to negative (and vice versa) is noticed particularly at intra decadal time spells (say, less than 100 months). The positive association (in-phase relationship) between sediment load and streamflow seems to indicate the dynamics of hydrological processes on the transport of suspended sediment in the river channel (Milliman and Syvitski 1992). Variations in the discharge characteristics of river flow determine the transport and suspended sediment fluxes and can help in understanding the factors and processes determining sediment responses. In general, the greater the flow, the more sediment will be transported (Sadeghi and Mostafazadeh 2016). Water discharge can be strong enough to suspend particles in the water column as they move downstream, or push them along the bottom of a water course. The negative relation between sediment load and streamflow implies that sediment load or streamflow was heavily influenced by other external factors such as human activities, which include flow diversion, construction of check dams etc., along with the construction of major control structures (Zhang et al. 2008). TDIC analysis performed for the streamflow and TSS concentration data from Tikrapara station (Fig. 11) shows similar trend in IMF1 and IMF2. Long range weak positive correlation between the two series is noticed in the inter-annual mode IMF3, with frequent reversals in the nature of correlation during the period 1980-1990. Unlike for the case of Basantpur station, in this station the modes are negatively correlated in long range in the low frequency modes IMF4 and IMF5. The strong negative association between streamflow and sediment concentration is more perceptible in the low frequency IMFs of the time series from Tikrapara station than that from Basantpur station. This could be attributed to the facts that the location of Basantpur is at upstream of major control structure Hirakud dam, while the location of Tikrapara is at far downstream of Hirakud dam. The influence of human interventions in the region might also be a reason for such negative association between streamflow and TSS concentration. From the TDIC analysis, it is found 

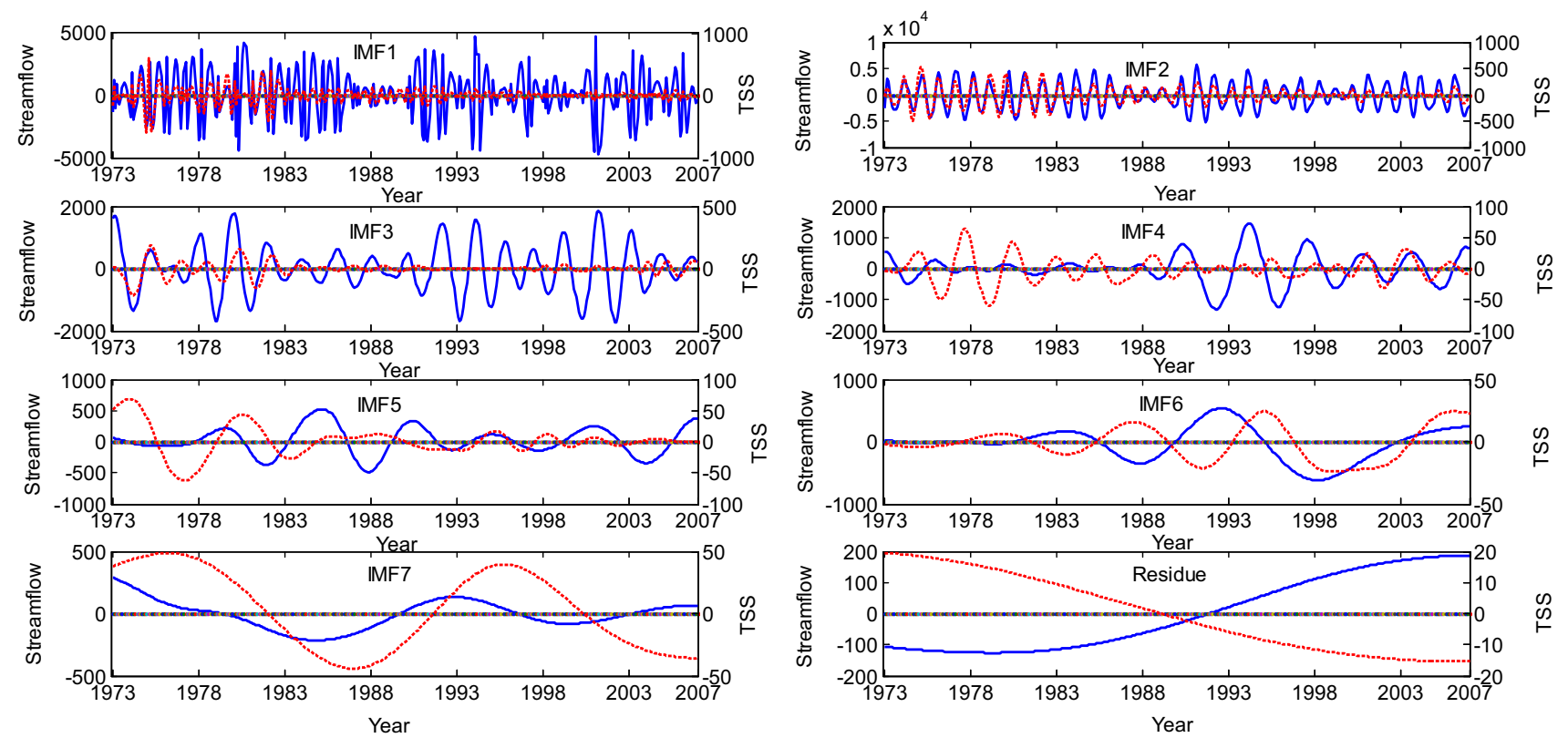

Fig. 9 Comparison of modes of streamflow with that of TSS concentration time series of Tikrapara station. The solid line (blue) represents the orthogonal mode of streamflow time series and dotted line (red) represents the orthogonal mode of TSS concentration series
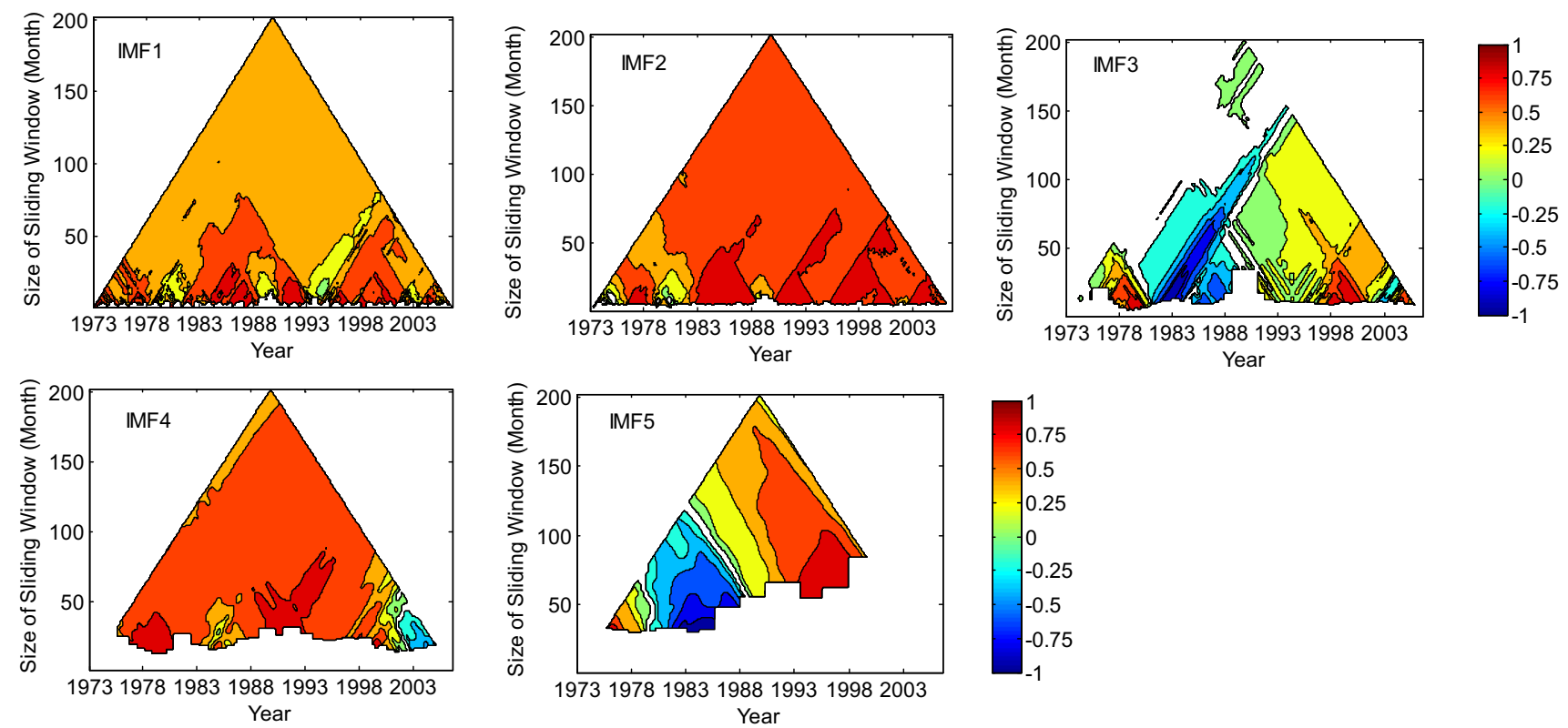

Fig. 10 TDIC plots of streamflow and TSS concentration data from Basantpur station. The void space in the TDIC plot means that the correlation coefficient is not significant at $5 \%$ significance level

that the nature of association between the streamflow and sediment vary in time domain and there can be frequent alterations in the nature of correlation. In the process of investigating the link between streamflow and sediment in a multiscaling framework, it is noticed that at certain time spells and certain scale a positive relation may prevail between the two, while in some other time spells and scale, the contrasting behavior may exist. Also there can be many couplets of alternating periods of such behavior in different IMFs. Eventhough an obvious reasoning is not possible to be adduced in this regard by the present study, it can be speculated that such transition in correlation may be attributed to some unidentified physical processes, the spatial non-homogenity of the basin or the influence of different climate forcings on the local hydrological processes. 

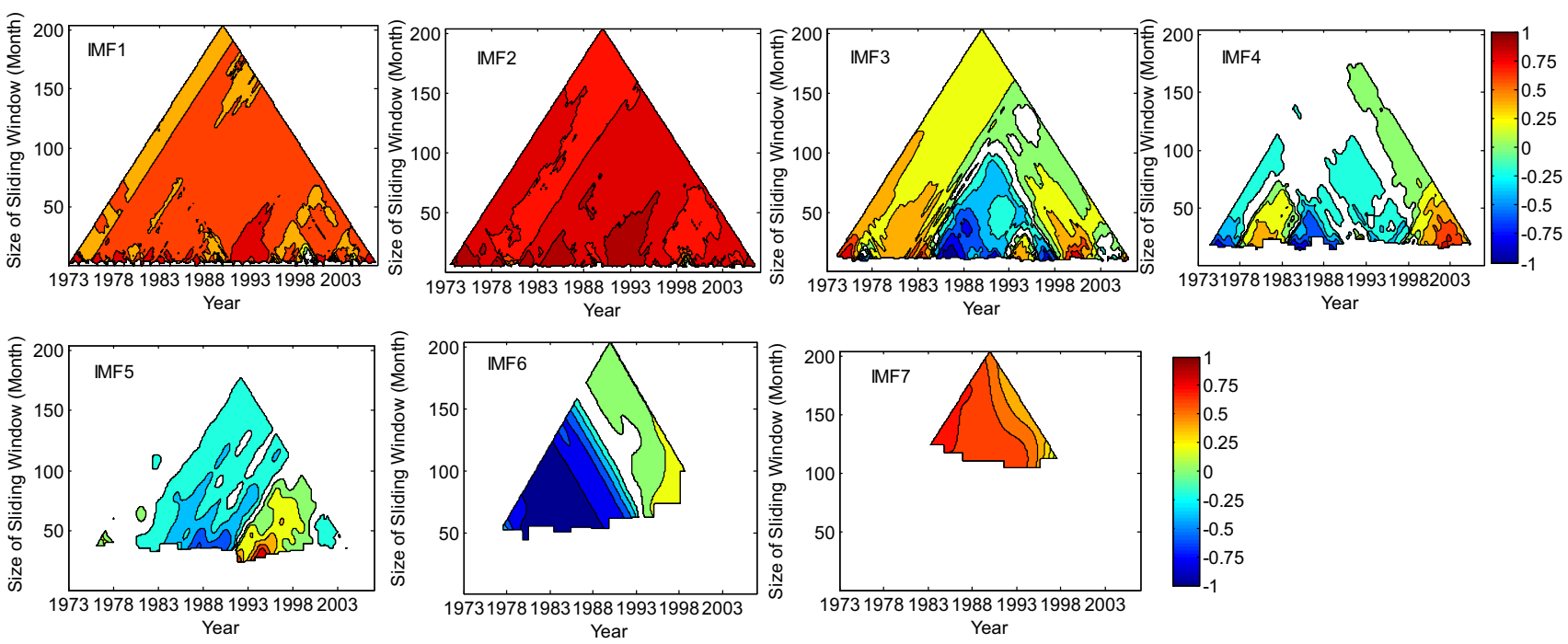

Fig. 11 TDIC plots of streamflow and TSS concentration data from Tikrapara station. The void space in the TDIC plot means that the correlation coefficient is not significant at $5 \%$ significance level

\section{Conclusions}

This paper proposed an effective methodology to investigate the linkage between streamflow and suspended sediment concentration in a multiscaling framework by employing the Hilbert-Huang transform (HHT) and time dependent intrinsic correlation (TDIC) analysis. First, the spectral analysis of streamflow and suspended sediment concentration time series of Basantpur and Tikrapara stations in Mahanadi basin, India is performed by the combining the use of the complete ensemble empirical mode decomposition with adaptive noise (CEEMDAN) method and normalized Hilbert transform-direct quadrature (NHTDQ) scheme. The Hilbert spectral representation proved the time varying property of dominant frequency of both of the time series. Then a cross correlation analysis of the modes of streamflow and TSS concentration is made, which proved a strong association between the two series at all of the time scales of variability. The results of correlation analysis showed that for both the stations, the association is positive in most of the high frequency modes and negative for the slowly varying residue component. The TDIC analysis showed the long range positive association between streamflow and sediment in both the stations, while the negative association between the two in interannual modes. The negative association is more perceptible at Tikrapara station which infers the human interventions are more influential in the streamflow and sediment concentration variability of this station. This analysis further proven that the nature and strength of association between streamflow and sediment is not of unique character both in time scale and in the time domain; and associated with frequent alterations on the nature of correlations (transition from positive to negative and vice versa).

Acknowledgements The authors offer their special and sincere thanks to Prof. Francois G. Schmitt, Director, Laboratory of Oceanology and Geosciences (LOG), University of Lille, Wimereux, France, for the scientific discussions on the HHT and TDIC methods held at LOG on October 29, 2014. The authors also acknowledge Prof. Yong-Xiang Huang, Associate Professor in the State Key Laboratory of Marine Environmental Science at Xiamen University, China, for providing the basic source code for TDIC analysis in the MATLAB platform at the website http://zenodo.org/record/9748? $1 \mathrm{n}=$ en for the promotion of non-commercial scientific research.

\section{References}

Adarsh S, Janga Reddy M (2015) Multiscale analysis of suspended sediment concentration data from natural channels using the Hilbert-Huang transform. Aquatic Procedia 4:780-788

Adarsh S, Janga Reddy M (2016) Analysing the hydroclimatic teleconnections of summer monsoon rainfall in Kerala, India using multivariate empirical mode decomposition and time dependent intrinsic correlation. IEEE Geosci Remote Sens Lett 13(9):1221-1225

Adarsh S, Vishnupriya MS, Narayanan S, Smruthi MS, George P, Benjie NM (2016) Trend analysis of sediment flux time series from tropical river basins in India using non-parametric tests and multiscale decomposition. Model Earth Syst Environ. doi:10. 1007/s40808-016-0245-0 (in press)

Ancey C, Böhm T, Jodeau M, Frey P (2006) Statistical description of sediment transport experiments. Phy Rev Earth 74:011302

Ancey C, Davison AC, Böhm T, Jodeau M, Frey P (2008) Entrainment and motion of coarse particles in a shallow water stream down a steep slope. J Fluid Mech 595:83-114

Antico A, Schlotthauer G, Torres ME (2014) Analysis of hydroclimatic variability and trends using a novel empirical mode decomposition: application to Parana river basin. J Geophy Res Atmos 119(3):1218-1233 
Barnhart BL, Eichinger WE (2011) Empirical Mode Decomposition applied to solar irradiance, global temperature, sunspot number and $\mathrm{CO}_{2}$ concentration data. $\mathbf{J}$ Atmos Solar Terr Phy 73(2011):1771-1779

Bedrosian E (1963) A product theorem for Hilbert transforms. Proc IEEE Trans 51:868-869

Cao Z, Li Y, Yue Z (2007) Multiple time scales of alluvial rivers carrying suspended sediment and their implications for mathematical modeling. Adv Wat Resour 30:715-772

Carson MA, Taylor CH, Grey BJ (1973) Sediment production in a small Appalachian watershed during spring runoff-EatonBasin, 1970-1972. Canadian J Earth Sci 10:1707-1734

Chen X, Wu Z, Huang NE (2010a) The time-dependent intrinsic correlation based on the empirical mode decomposition. Adv Adapt Data Anal 2:233-265

Chen YD, Zhang Q, Xu C-Y, Lu X, Zhang S (2010b) Multiscale streamflow variations of the Pearl River basin and possible implications for the water resource management within the Pearl River delta. China. Quat. Int 226:44-53

Derot J, Schmitt FG, Gentilhomme V, Morin P (2016) Correlation between long term marine temperature time series from eastern and western English channel: scaling analysis using empirical mode decomposition method. Comptes Rendus Geosc. doi:10. 1016/j.crte.2015.12.001

Farnsworth KL, Milliman JD (2003) Effects of climatic and anthropogenic change on small mountainous rivers: the Salinas River example. Glob Planet Chang 39:53-64

Flandrin P, Gonçalvès P (2004) Empirical mode decompositions as data-driven wavelet-like expansions. Int $\mathrm{J}$ Wavelets Multi 2(4):477-496

Flandrin P, Rilling G, Gonçalvè P (2004) Empirical mode decomposition as a filter bank. IEEE Signal Process Lett 11(2):112-114

Florsheim JL, Pellerin BA, Oh NH, Ohara N, Bachand PAM, Bachand SM, Bergamaschi BA, Hernes PJ, Kavvas ML (2011) From deposition to erosion: spatial and temporal variability of sediment sources, storage, and transport in a small agricultural watershed. Geomorphol 132:272-286

Franceschini S, Tsai CW (2010) Application of Hilbert-Huang transform method for analyzing toxic concentrations in the Niagara River. J Hydrol Eng 15(2):90-96

Gadgil S, Vinayachandran PN, Francis PA, Gadgil S (2004) Extremes of the Indian summer monsoon rainfall, ENSO and equatorial Indian Ocean oscillation. Geophy Res Lett 31:L12213. doi:10. 1029/2004GL019733

Gao P, Pasternack GB, Bali KM, Wallender WW (2007) Suspendedsediment transport in an intensively cultivated watershed in south eastern California. Catena 69:239-252

Gray AB, Pasternack GB, Watson EB, Warrick JA, Goni MA (2014) The effect of El Niño Southern Oscillation cycles on the decadal scale suspended sediment behaviour of a coastal dry-summer subtropical catchment. Earth Surf Proc Land. doi:10.1002/esp. 3627

Gupta H, Chakrapani GJ (2005) Temporal and spatial variations in water flow and sediment load in Narmada river Basin, India: natural and man-made factors. Environ Geol 48:579-589

Huang Y, Schmitt FG (2014) Time dependent intrinsic correlation analysis of temperature and dissolved oxygen time series using empirical mode decomposition. J Marine Syst 130(2014):90-100

Huang NE, Wu Z (2008) A review on Hilbert-Huang transform: method and its applications to geophysical studies. Rev Geophys. doi:10.1029/2007RG000228

Huang NE, Shen Z, Long SR, Wu MC, Shih HH, Zheng Q, Yen NC, Tung CC, Liu HH (1998) The empirical mode decomposition and the Hilbert spectrum for nonlinear and non-stationary time series analysis. Proc Royal Soc A 454:903-995
Huang Y, Schmitt FG, Lu Z, Liu Y (2009a) Analysis of daily river flow fluctuations using empirical mode decomposition and arbitrary order Hilbert spectral analysis. J Hydrol 454:103-111

Huang NE, Wu Z, Long SR, Arnold KC, Blank K, Liu TW (2009b) On instantaneous frequency. Adv Adapt Data Anal 1(2):177-229

Ismail DK, Lazure P, Puillat I (2015) Advanced spectral analysis and cross correlation based on empirical mode decomposition: application to the environmental time series. Geosci Remote Sens Lett 12(9):1968-1972

Janga Reddy M, Adarsh S (2016) Time frequency characterization of subdivisional scale seasonal rainfall in India using HilbertHuang transform. Stoch Envir Res Risk Assess 30(4):1063-1085

Kuai KZ, Tsai CW (2012) Identification of varying time scales in sediment transport using the Hilbert-Huang transform method. J Hydrol 420-421:245-254

Lyn DA (1987) Unsteady sediment-transport modeling. J Hydraul Eng 113(1):1-15

Maity R, Nagesh Kumar D (2008) Basin-scale streamflow forecasting using the information of large-scale atmospheric circulation phenomena. Hydrol Process 22(5):643-650

Marusiak O, Pekar J (2014) Analysis of multiannual fluctuations and long term trends of hydrological time series. Proc of Advances in Environmental Sciences, Development and Chemistry 17-21 July 2014 Greece, pp 156-159

Massei N, Fournier M (2012) Assessing the expression of large scale climatic fluctuations in the hydrologic variability of daily Seine river flow (France) between 1950 AND 2008 using HilbertHuang transform. J Hydrol 448-449(2012):119-128

Milliman JD, Syvitski JPM (1992) Geomorphic/tectonic control of sediment discharge to the ocean: the importance of small mountainous rivers. J Geol 100:525-544

Nuttal AH (1966) On the quadrature approximation to the Hilbert transform of modulated signals. Proc IEEE Trans 54(10):1458-1459

Panda DK, Kumar A, Mohanty S (2011) Recent trends in sediment load of the tropical (Peninsular) river basins of India. Glob Planet Chang 75(2011):108-118

Papadimitriou S, Sun J, Yu PS (2006) Local correlation tracking in time series. Proceedings of Sixth International Conference on Data Mining IEEE Computer Society Washington, DC, USA, pp 456-465

Rao AR, Hsu EC (2008) Hilbert-Huang transform analysis of hydrological and environmental time series. Springer, Netherlands

Rodo X, Rodriguez-Arias MA (2006) A new method to detect transitory signatures and local time/space variability structures in the climate system: the scale-dependent correlation analysis. Clim Dyn 27:441-458

Rudi J, Pabel R, Jager G, Koch R, Kunoth A, Bogena H (2010) Multiscale analysis of hydrologic time series data using the Hilbert-Huang transform. Vadose Zone J 9:925-942

Sadeghi SHR, Mostafazadeh R (2016) Triple diagram models for changeability evaluation of precipitation and flow discharge for suspended sediment load in different time scales. Envir Earth Sci. doi:10.1007/s12665-016-5621-6

Syvitski JPM (2003) Supply and flux of sediment along hydrological pathways: research for the 21st century. Glob Planet Chang 39:1-11

Syvitski JPM, Vörösmarty CJ, Kettner AJ, Green P (2005) Impact of humans on the flux of terrestrial sediment to the global coastal ocean. Science 208:376-380

Thompson SE, Katul GG (2012) Multiple mechanisms generate Lorentzian and $1 / \mathrm{f}^{\alpha}$ power spectra in daily stream-flow time series. Adv Wat Resour 37(2012):94-103

Torres ME, Colominas MA, Schlotthauer G, Fladrin P (2011) A complete ensemble empirical mode decomposition with adaptive 
noise. IEEE International conference on Acoustic Speech and Signal Processing, Prague, pp 4144-4147

Walling DE, Fang D (2003) Recent trends in the suspended sediment loads of the wet season over different river basins of India. Indian Institute of Tropical world's rivers. Glob Planet Chang 39:111-126

Warrick JA, Mertes LAK (2009) Sediment yield from the tectonically active semiarid Western Transverse Ranges of California. Geol Soc Am Bull 121:1054-1070

Wu Z, Huang NE (2004) A study of the characteristics of white noise using the empirical mode decomposition method. Proc Royal Soc A 460(2046):1597-1611

Wu Z, Huang NE (2005a) Ensemble empirical mode decomposition: A noise-assisted data analysis method. Centre for Ocean-LandAtmospheric Studies Technical Report. 193, Centre for OceanLand-Atmos. Stud., Calverton, Md, pp 1-51 (ftp://grads.iges.org/ pub/ctr/ctr_193.pdf)
Wu Z, Huang NE (2005b) Statistical significant test of intrinsic mode functions. In: Huang NE, Shen SSP, Hilbert-Huang transform: introduction and applications, World Scientific, Singapore, pp $125-148$

Zhang Q, Chen G, Su B, Disse M, Jiang T, Xu C-Y (2008) Periodicity of sediment load and runoff in the Yangtze river basin and possible impacts of climatic changes and human activities. Hydrol Sci J 53(2):457-464

Zhang Q, Xu C-Y, Singh VP, Yang T (2009) Multiscale variability of sediment load and streamflow of the lower Yangtze river basin: possible causes and implications. J Hydrol 368:96-104

Zhang Q, Xu C-Y, Chen X, Lu X (2012) Abrupt changes in the discharge and sediment load of the Pearl River, China. Hydrol Process 26:1495-1508

Zhang Q, Singh VP, Li K, Li J (2014) Trend, periodicity and abrupt change in streamflow of the East River, the Pearl River basin. Hydrol Process 28:305-314 